\title{
Bovine Tuberculosis and Badger Control in Britain: Science, Policy and Politics
}

\author{
Steven P. McCulloch ${ }^{1} \cdot$ Michael J. Reiss $^{2}$
}

Accepted: 31 July 2017/Published online: 24 August 2017

(C) The Author(s) 2017. This article is an open access publication

\begin{abstract}
Bovine tuberculosis (bovine TB) is the most economically important animal health policy issue in Britain. The problem of what to do about badgers has plagued successive governments since a dead badger was discovered with bovine TB in 1971. Successive Labour governments (1997-2010) oversaw the Randomised Badger Culling Trial (RBCT) from 1998 to 2006. Despite the RBCT recommendation against culling, the 2010-2015 Coalition government implemented pilot badger culls. This paper provides an account of the evolution of bovine TB and badger control policy, focusing on the 1997-2010 Labour, the 2010-2015 Coalition and the 2015-present Conservative governments. Interviews with bovine TB policy stakeholders supplement discussion of the development of bovine TB policy. The paper discusses the science and politics of bovine TB policy, in which there are different badger control policies in Westminster, Welsh and Scottish governments. Badger control is a highly polarised issue, and the Coalition and Conservative governments have been heavily criticised for a culling policy opposed by the independent scientific community. Recent governments have defended badger culling on the basis of veterinary advice and experience in countries such as New Zealand. The paper concludes with two key recommendations to inform controversial animal health and welfare policy issues such as bovine TB. First, mandatory Animal Welfare Impact Assessment provides objective data on the impacts of policy options on cows and badgers. Second, robust ethical analysis, conducted by
\end{abstract}

Michael J. Reiss

m.reiss@ucl.ac.uk

Steven P. McCulloch

Steven.McCulloch@winchester.ac.uk

1 University of Winchester, Sparkford Road, Winchester SO22 4NR, UK

2 UCL Institute of Education, University College London, 20 Bedford Way, London WC1H 0AL, UK 
independent experts using established moral frameworks, should be applied to animal health and welfare issues for the benefit of decision makers.

Keywords Animal health and welfare policy · Animal Welfare Impact Assessment (AWIA) · Badger culling · Badger vaccination · Bovine tuberculosis - Ethical analysis

\section{Introduction}

Bovine tuberculosis (bovine TB) is the most important animal health and welfare policy issue in Britain. This paper provides an overview of the science, policy and politics of bovine TB in Britain, with a focus on the highly controversial issue of badger culling. The first part of the paper documents the interviewing methodology used to inform discussion in this and related papers (McCulloch and Reiss $2017 \mathrm{a}, \mathrm{b}, \mathrm{c}, \mathrm{d})$. The second part of the paper provides a chronological overview of bovine TB policy and the issue of badger culling. The third part of the paper briefly discusses how the contested scientific evidence base, plural values and political factors influence bovine TB policy. In the final part of the paper, a case is made for the inclusion of Animal Welfare Impact Assessment (AWIA) and ethical analysis to inform animal health and welfare policy such as bovine TB and badger control.

\section{Animal Health and Welfare Policy Interviews}

As part of the research undertaken for this paper, the first author conducted semistructured interviews with animal health and welfare policy actors. The interviews were conducted between 2012 and 2013. Seventeen individuals were interviewed. Interviewees were primarily selected based on their roles giving them knowledge of the animal health and welfare policy process. Interviewees were given the option of whether to be identified or to remain anonymous. Hence, in the quotations from transcripts in this paper, some actors are identified, whereas others are labelled with reference to their professional role and affiliation. Interviewees include a former government minister, a retired Department for Environment, Food and Rural Affairs (Defra) civil servant, an Animal Health and Welfare Board of England (AHWBE) ${ }^{1}$ member, a former President of the British Cattle Veterinary Association (BCVA), a National Farmers Union (NFU) TB policy official and Professor John Bourne, the Chair of the Independent Scientific Group (ISG), which conducted the Randomised Badger Culling Trial (RBCT). Interviews, which were digitally audio-recorded, lasted for up to three hours (an hour typically) and the material was transcribed and thematically coded for analysis. The interviews covered a range of issues related to the broader project on animal health and welfare policy with discussion of bovine TB one part of the interview.

\footnotetext{
1 The Animal Health and Welfare Board of England is the principal advisory body to Defra on strategic issues relating to health and welfare.
} 


\section{Bovine Tuberculosis}

Bovine TB is a notifiable zoonotic disease ${ }^{2}$ of cows caused by the bacterium Mycobacterium bovis. In 1934, 40\% of dairy cows in Britain were infected with bovine TB and at least $0.5 \%$ of these produced tuberculous milk. Bovine TB was estimated to cause 2500 human deaths and 50,000 new cases arose each year (Reynolds 2006). Up to 30\% of cattle in Britain died from bovine TB in the 1930s (Grant 2009). The pasteurisation of milk, which began in 1935, has effectively prevented transmission of $M$. bovis to humans, although transmission is still possible by aerosol spread or by consumption of unpasteurised milk (Defra 2014b) .

\section{Early Government Policy}

The British government encouraged voluntary eradication of bovine TB as early as 1923. In 1935, a national programme of attesting herds to be free of disease began. This became a compulsory eradication scheme in 1950 (Grant 2009). This scheme involved testing cattle for bovine TB and slaughtering those which reacted to the test. The herd was considered as the infectious unit, which resulted in a number of whole herds being slaughtered [John Bourne, Chair ISG]. Movement restrictions were put in place on herds which suffered reactors. To achieve attested status, a herd had to pass three consecutive tuberculin tests. Attested herds could only buy in cattle from other attested herds. Attested herds also had to demonstrate biosecurity measures.

In 1960 the whole of Britain had become an attested area and in that decade it was widely believed that bovine TB had been brought under control (Grant 2009). Due to the improving situation, herd testing frequency was relaxed and in 1979 less than $0.5 \%$ of the national herd was infected. However, these herds were geographically concentrated in a few small pockets in the south west (Defra 2014b). With the lifting of restrictions, these areas were never cleared of disease and today remain as hotspots of the disease in cattle [John Bourne, Chair ISG].

McEldowney et al. (2013) report how the chief veterinarian at the time claimed the end of attestation would result in an increase in bovine TB. When the attested scheme was lifted, the incidence of bovine TB did indeed subsequently increase. Bourne claimed that the ending of the attested herd scheme, together with a move to regard the individual animal and not the herd as the infectious unit, led to resurgence of the disease [John Bourne, Chair ISG]. Godfray et al. (2013) report a meta-analysis study that found the tuberculin skin test has only a $49 \%$ sensitivity at herd-level. This would mean that the tuberculin skin test misses around half of infected herds.

\section{Bovine TB and Badgers}

In 1971, a dead badger found in Gloucestershire was found to be infected with $M$. bovis. The discovery of bovine TB in badgers led to badger culling commencing in

\footnotetext{
2 A notifiable disease is one which must be reported to regulatory authorities by law. A zoonotic disease is one which is transmissible from animals to humans.
} 
1973. Initially, licences to kill badgers were issued to farmers under the Badgers Act 1973. The badgers were killed either by cage-trapping and shooting or by freeshooting. In part due to concerns about the welfare of badgers being shot by farmers, the Ministry of Agriculture, Fisheries and Farming (MAFF) ${ }^{3}$ took over the role of culling in 1975. MAFF culled the badgers by gassing setts with hydrogen cyanide, under a provision in the Conservation of Wild Creatures and Wild Plants Act 1975 (Spencer 2011). Further concerns about the welfare of badgers led to the first of a number of reviews on bovine TB and badgers. The following discussion of the Zuckerman and Dunnet reviews is informed by Spencer (2011, p. 93).

A review by Lord Zuckerman found that badgers were a reservoir of infection and proposed a 'clean ring' strategy (Zuckerman 1980). The clean ring strategy involved sampling badgers around infected farms and culling a whole sett if badgers tested positive. Further adjacent setts would then be tested and culled if positive until no further M. bovis-infected badgers were found. The process would continue for six months to maintain a 'clean ring' around the farm.

The Dunnet report was the follow up review of Zuckerman's clean ring strategy (Dunnet et al. 1986). Dunnet et al. found that the incidence of bovine TB across Great Britain had reduced whether or not badgers had been culled in the area. Furthermore, the costs of the clean ring strategy were considered to be unsustainable. For these reasons, an interim strategy was proposed. The interim strategy involved farmers taking biosecurity measures to reduce the potential for cattle-to-badger contact. Additionally, badgers were culled where it was reasonably suspected that herd breakdowns were caused by badgers. The culling was confined to the farmer's own land and the infected herd. Despite the intentions of the interim strategy to be a short term policy, it continued from 1986 to 1997, in part because of MAFF's focus on BSE.

Professor Sir John Krebs ${ }^{4}$ chaired the third government-commissioned review into bovine TB (Krebs et al. 1997). The Krebs report found badgers to be a "significant source of infection in cattle" but said that the evidence was "indirect" as it consisted of correlations and not cause and effect (Krebs et al. 1997, p. 6). The Krebs report recommended an experimental trial to quantify the impact of badger culling on bovine TB.

\section{The RBCT, the King Review and Hilary Benn's Decision}

The government appointed Professor John Bourne to Chair the Independent Science Group (ISG), which designed and conducted the trial proposed by Krebs. The Randomised Badger Culling Trial (RBCT) began in 1998 and ran until 2006, being interrupted in 2001 by the foot and mouth epidemic. The RBCT was conducted in areas of high incidence of bovine TB. The trial consisted of ten sets of 'triplets', each composed of a proactive-culling area, a reactive-culling area and a survey-only area. Reactive culling was abandoned early in the trial as it was found to increase,

\footnotetext{
${ }^{3}$ MAFF was dissolved and replaced by Defra in 2011, in part due to failings and perceived conflicts of interests that arose during the Bovine Spongiform Encephalopathy (BSE) inquiry.

${ }^{4}$ Professor Krebs has since been appointed to the House of Lords.
} 
rather than decrease, the incidence of TB in cattle. In the reactive cull areas badgers were killed when there was an outbreak of TB in cattle. Proactive culling of badgers was found to reduce the incidence of bovine TB in cattle in the culling area by $19 \%$. However, proactive culling was associated with a $29 \%$ increase in bovine TB in the area outside the culling area (Bourne et al. 2007; Donnelly et al. 2006). The increase in bovine TB outside of the culling area was due to the perturbation effect, in which culling caused changes in the social behaviour of badgers including greater ranging outside their normal territory (Bourne et al. 2007; Woodroffe et al. 2006).

As a result of these early ISG findings, the government introduced pre-movement testing of cattle and changed the compensation scheme to farmers for loss of cattle due to TB. In addition, a public consultation was launched on badger culling. The consultation documents included the information that badger culling could be an effective method to control TB in cattle and that veterinary advice supported a cull. The ISG criticised the document on the basis that it did not accurately portray the findings to date [John Bourne, Chair ISG]. Despite the government's presentation of information in the consultation document, $95.6 \%$ of respondents were opposed to badger culling (Defra 2006).

In June 2007 the ISG submitted its Final report to government. The report concluded that "badger culling can make no meaningful contribution to cattle TB control in Britain" (Bourne et al. 2007). Bourne and his team found that although badgers contribute to the disease, bovine TB is mostly a problem of cattle-to-cattle transmission that can be solved by cattle-based controls:

Scientific findings indicate that the rising incidence of disease can be reversed, and geographical spread contained, by the rigid application of cattle-based control measures alone. (Bourne et al. 2007)

This conclusion was unexpected, and indeed unwelcome, to some in the animal health and welfare community. As a former Labour Defra minister involved at the time reported: "When I arrived [at Defra] ... John Bourne's ISG report basically was on the desk. And I suppose what it said was not quite what people, or some people, expected" [Former Defra Minister, Labour Party]. Bourne reported that from the start of the trial it was expected future policy in Defra would be based on reactive culling [Bourne, Chair ISG]. ${ }^{5}$ After the ISG submitted its Final report, the government asked its Chief Scientific Adviser to review the evidence. ${ }^{6}$ In contrast to the ISG, the King review found that badger culling "could make a significant contribution to the control of cattle TB in those areas of England where there is a high and persistent incidence of $\mathrm{TB}$ in cattle, provided removal takes places alongside an effective programme of cattle controls" (King 2007 para. 51).

\footnotetext{
5 "There was a very definite view from the outset that future policy was going to be the reactive culling. That was it. And when it was shown that it was not gonna work there was all hell let loose" [John Bourne, Chair ISG].

${ }^{6}$ Sir David King worked with five other scientists: Prof. Tim Roper (ecologist), Prof. Douglas Young (immunologist/microbiologist), Prof. Mark Woolhouse (epidemiologist), Prof. Dan Collins (veterinary medicine) and Dr Paul Wood (veterinary microbiologist/immunologist).
} 
Despite King's findings, Hilary Benn, the then Secretary of State for Defra, found the evidence of the ISG more persuasive. He announced to Parliament in July 2008 his decision not to go ahead with a cull:

Having listened carefully to a wide range of views from scientists, farming, veterinary and wildlife organisations, and many others, and having considered all the evidence, I have decided that although such a cull might work, it might also not work. It could end up making the disease worse if the cull was not sustained over time or delivered effectively, and public opposition, including the unwillingness of some landowners to take part, would render that more difficult. It would not be right to take that risk. (HC Deb 2008)

Benn's decision was celebrated by the anti-cull lobby, including the Royal Society for the Protection of Cruelty to Animals (RSPCA), the Badger Trust and the left wing press. It was criticised by the Conservative Party, the NFU, the British Veterinary Association (BVA) and the right wing press.

\section{0 and a Change in Government}

The British public returned no clear majority in the 2010 general election and the Conservative Party formed a Coalition government with the Liberal Democrats. The Conservative Party had opposed Benn's decision in Parliament and favoured a cull of badgers (HC Deb 2008). Both parties represented a large number of constituencies in rural areas and the Liberal Democrats had a significant base in the south west of England, where the disease was endemic. The new government confirmed its policy of a "carefully managed and science-led policy of badger control" in its Coalition Agreement (HM Gov 2010, p. 18).

Due to the economic recession, the government had an overarching deficit reduction and cost sharing programme. The conclusions of the ISG were in part based on the practicality, including economic sustainability, of a government-led cull (Bourne et al. 2007). Due to the economic costs of delivering a cull, the government proposed a farmer- and landowner-led cull (Defra 2010a). Farmers and landowners would be granted licences by Natural England under the Protection of Badgers Act 1992 and the Countryside Act 1981. ${ }^{7}$ The government proposed that the culls must take place in areas of at least $150 \mathrm{~km}^{2}$, where the cull company employed by the farmers and landowners had access to over $70 \%$ of the land area. The costs of monitoring and licences would be paid for by government but the farming industry would pay for delivering the actual cull (Defra 2011). A NFU bovine TB official outlined the organisation's position on the culls:

We know that if you cull badgers in a proactive, sustained manner, not reactive culling, proactive culling, so removing large numbers from a relatively large area, and that's sustained for a period of 4 years, we know

\footnotetext{
7 The Welsh Assembly proposed a badger cull in Wales under the Animal Health Act 1981. This was found to be unlawful under judicial review when challenged by the Badger Trust. The judge cited one reason as the estimated reduction in bovine TB being "modest" and not "substantial" (Spencer 2011, p. 97).
} 
from the RBCT that we're getting $30+\%$ reduction, that persisted you know 4-5 years after culling. So the principle of culling the badgers has been made. Even based on the way that they did in the RBCT, the issue the ISG had is with cost of delivering the cull ... what we're saying is industry will come together and deliver the cull, and industry will pick up those costs, so in effect it is cost sharing in practice. So we've said in industry, yes you've [government] caused this problem by lots of inaction, but we're actually prepared to pick up and run with this and deliver a policy [NFU official, TB policy]

The government published a veterinary assessment of the risk factors associated with the cull. In particular, for the cull to be effective, it must mitigate against perturbation of badgers (Defra 2010b). The government also encouraged the licensed BadgerBCG vaccine to be deployed to mitigate perturbation (Defra 2010a). In the consultation document the government stated that if a different culling strategy were employed to that used in the RBCT "the effect on TB incidence and the degree of the resulting perturbation is uncertain". In addition, the veterinary assessment stated it to be "essential" that culling is done using methods that are "both effective and humane" (Defra 2010b; HC 2013, p. 8).

The government announced in January 2012 that two pilot culls would take place in west Somerset and west Gloucestershire. The culls were planned to commence in summer 2012 but were delayed until 2013 for three reasons. First, the 2012 London Olympic Games put pressure on police resources to oversee the cull. Secondly, the Badger Trust challenged the legality of the cull in the High Court. Thirdly, the NFU had written to the minister to request the cull be postponed until 2013. This was because of recent fieldwork which estimated the badger population was higher than originally expected (HC 2013). It was the latter reason that led to the national press mocking Owen Paterson, the Secretary of State for Defra, for claiming that the badgers had "moved the goalposts" (BBC 2013). The government's broader approach to bovine TB was to divide the country into three geographical areas based on risk. These were the 'high risk area', the 'low risk area' and the 'edge area'. The high risk and edge areas would be subject to more stringent cattle controls. Badger culling would take place in high risk areas, with some vaccination of badgers in the edge area (Defra 2013).

The Queen guitarist and animal rights activist Brian May played an active role in the badger culling debate. May set up the Save Me trust during the 2010 general election campaign to oppose Conservative Party policies to give Parliament a free vote to repeal the Hunting Act and to introduce a badger cull. Later, May was instrumental in setting up Team Badger, a coalition of national and local organisations against badger culling. ${ }^{8}$

\footnotetext{
8 The Team Badger coalition included the Badger Trust, the Wildlife Trusts, International Fund for Animal Welfare (IFAW), Born Free Foundation (BFF), RSPCA, Save Me, League Against Cruel Sports (LACS), People for the Ethical Treatment of Animals (PETA), Animal Aid, Animal Defenders International (ADI) and many local wildlife and badger protection organisations.
} 


\section{The Pilot Culls}

The Coalition government announced in August 2013 that the pilot culls had commenced. Requests for extensions to the cull were granted in both Somerset and Gloucestershire due to an insufficient number of badgers being culled. The Somerset pilot culled $<48 \%$ of badgers and was extended from six to 9 weeks. The Gloucestershire pilot culled $<39 \%$ and was extended from six to 11 weeks (HC 2013; IEP 2014). The target in both Somerset and Gloucestershire was to cull $70 \%$ of the badger population.

In interview, a former BCVA President spoke of the importance of humane culling of badgers:

As BCVA President when I spoke to the Secretary of State ... I said that the absolutely key thing to do was it has to be done humanely. And I'm sure she came to that conclusion long before I came to her. But that, as a veterinary surgeon I felt that was an essential message to get across. [Former BCVA President]

In February 2014, the BBC reported leaked findings of the expert group auditing the pilot culls. The Independent Expert Panel (IEP) was charged with overseeing the efficacy, safety and humaneness of the culls. The BBC reported that the pilot culls had failed both the efficacy and humaneness tests. A parliamentary backbench motion on 14 March to stop further culling was passed by 200 votes to 1 (HC Deb 2014). The IEP report was later published and had found that 7.4-22.8\% of badgers took longer than 5 min to die (IEP 2014). The government humaneness target had been that $<5 \%$ of badgers should take over $5 \mathrm{~min}$ to die.

Subsequently, Defra announced the culls would not be rolled out across the country in 2014, but that the pilot culls in Somerset and Gloucestershire would continue annually. Dyer has claimed that Nick Clegg, the Deputy Prime Minister and leader of the Liberal Democrats, concerned about the unpopularity of the cull and the IEP report, withdrew his support for extending the pilot culls into Devon and Cornwall until the problems with effectiveness and humaneness were resolved (Dyer 2016) . ${ }^{9}$ The IEP was disbanded after the first year of the pilot culls, despite the findings of serious problems with effectiveness and humaneness of the culls. Owen Paterson stated that lessons would be learned to improve future culls, and there was greater emphasis on the use of badger vaccination (Defra 2014a). The Chief Veterinary Officer (CVO) would provide a written report on later annual culls to replace the IEP audit.

\section{The 2015 Conservative Government Policy on Badger Control}

The 2015 general election resulted in an overall majority for the Conservative Party, with the Liberal Democrats being decimated at the polls. The Conservative Party had pledged to implement its 25-year strategy to eradicate bovine TB, which

\footnotetext{
${ }^{9}$ Dominic Dyer wrote Badgered to Death: The People and Politics of the Badger Cull based on his experience as Chief Executive of the Badger Trust, a leading campaign group against the cull.
} 
included badger culling, in its manifesto (Conservative Party 2015). The unpopularity of the badger cull can be inferred from the manifesto's simple statement to "implement our 25-year strategy to eradicate bovine TB", and the complete omission of any reference to badgers or wildlife (Conservative Party 2015, p. 21).

The government announced a third culling area, in Dorset, to commence in 2015. The decision to continue free shooting of badgers and roll its policy out to Dorset led to a further open letter to the government by eminent bovine TB experts (Barkham 2015; Bateson et al. 2015). The letter, organised by the veterinarian Mark Jones of the Born Free Foundation, questioned the scientific basis of the cull and called on the government to reconsider its policy. It was signed by, amongst others, Professor John Krebs, Professor John Bourne and Professor Ranald Munro. Hence, the Chairs of the three major recent scientific reviews on badger culling-the Independent Scientific Review Group (Krebs), the Independent Scientific Group (Bourne) and the Independent Expert Panel (Munro)—openly expressed opposition to the continued government culls. In their letter, the scientists also pointed to the lack of economic grounds for a cull. A Freedom of Information request by the Badger Trust revealed that the cost of culling a single badger was £6775. In response to this criticism, the government claimed that farmers were paying for the majority of costs and that costs are reducing with further culls (BBC News 2015).

The BVA withdrew its support for the free shooting of badgers in 2015 after the second year of culls failed to improve the humaneness criteria (BVA 2015). Despite the government policy of permitting both free shooting and cage-trapping and shooting, the BVA continued its support of the government's badger culling policy in general. As a result of internal disagreement in the BVA, it's Ethics and Welfare Group was disbanded and replaced by a weaker Ethics and Welfare Advisory Panel.

Culling began in seven further areas in 2016 in the counties of Herefordshire, Gloucestershire, Cornwall, Devon and Dorset (Defra 2016b). These culls led to a Westminster debate on badger culling and bovine TB in September 2016, secured by the Scottish Nationalist Party (SNP) MP Dr Paul Monaghan. Paul Monaghan stated the following in his opening speech opposing badger culling: "No substantial or respectable body of scientific work has ever been produced to contradict the conclusions of the Independent Scientific Group on Cattle TB” (HC Deb 2016).

In general, Conservative Members of Parliament supported a continued cull as an unfortunate but necessary policy to combat bovine TB. Labour MPs were opposed to badger culling and criticised the scientific case for government policy. Those opposed to culling also argued that spending $£ 6000-7000$ per badger culled could not be justified on economic grounds, especially in a broader context of economic austerity. Given the importance of the economic justification for culling to government, Defra published a Badger control policy: value for money analysis report. The report concluded that the benefits of culling should outweigh the costs by $£ 0.56$ million per culling area over 4 years, despite advising "considerable uncertainty" about the figures (Defra 2016a, p. 2).

A further petition against the cull across 2016-2017 surpassed the required 100,000 signatures to be debated in Parliament. Paul Flynn MP (Labour) moved the motion to consider the petition. Flynn called for the "walls of Government prejudice to come down" and for the adoption of a "scientific and humane" approach (HC 
Deb 2017). The subsequent debate covered the various bovine TB approaches of the devolved UK nations, other countries such as New Zealand and Australia, inadequacies of the diagnostic skin test, biosecurity and economics of bovine TB. The Minister of State for Agriculture, Fisheries and Food, George Eustice, ${ }^{10}$ gave the government response. After describing the government's approach to bovine TB, he urged Parliamentarians to keep some perspective. He claimed, based on veterinary advice, that a badger cull was necessary to eradicate bovine TB. He finished by putting the following moral question to Parliament: "Is it really that different from the approach that we take to controlling other wildlife, such as foxes, or deer in royal parks?" (HC Deb 2017).

The Conservative Party had promised a referendum on continued EU membership in its 2015 general election manifesto. The Prime Minister David Cameron campaigned to remain in the EU. However, in 2016 the British public narrowly voted to leave the EU. Cameron resigned and was replaced as leader of the Conservative Party and Prime Minster by Theresa May. To increase her majority and strengthen the government's negotiating stance on Brexit, May called a snap general election for 8 June 2017.

\section{The 2017 Minority Conservative Government}

Theresa May's plan backfired and the British public returned a minority Conservative government, supported by a confidence and supply deal with the Democratic Unionist Party (DUP). The Conservative Party manifesto had not mentioned badger culling (Conservative Party 2017), whilst the Labour Party pledged to end the cull (Labour Party 2017). Michael Gove was appointed as Secretary of State for Defra and George Eustice continued as the Food and Farming Minister. Gove promised to review the evidence on bovine TB and badger culling. Less than a week later, he reaffirmed the government's position on badger culling in an interview with the Farmers Guardian (Kay 2017).

\section{Contested Science, Plural Values and Political Factors}

That the badger has a role in the transmission of the disease to cattle is widely accepted. The nature of the disagreement revolves around two key questions. First, how much of a role does the badger play? Secondly, are there effective, practical and socially acceptable measures which can reduce the transmission?

The question about effectiveness arises because culling causes perturbation in badgers, where they roam outside of their normal ranges, which can have the effect of increasing transmission of disease. The costs of cage-trapping and shooting, the method of culling used in the RBCT, is prohibitively high to conduct on a sufficiently large scale. Compounding these constraints, the behaviour and anatomy of the badger make the cheaper option of controlled/free-shooting problematic.

\footnotetext{
${ }^{10}$ George Eustice has a farming background and his family has a herd of South Devon cattle in Cornwall, an area of the UK with a high incidence of bovine TB.
} 
Badgers are a nocturnal, low slung and muscular species, meaning there is a high risk of suboptimal culling, resulting in welfare problems for wounded animals.

These two questions have been debated in the public arena by leading scientists in national newspapers. Ian Boyd, the Defra Chief Scientific Adviser, and Nigel Gibbens, the CVO, have argued the government's case for badger culling in The Guardian (Boyd and Gibbens 2012). Boyd and Gibbens cite evidence from other countries where wildlife control has assisted TB control, the future potential, but current limitations, of cattle and badger vaccination, and stress that badger culling is part of a wider package of disease control measures (Boyd and Gibbens 2012).

In response, Professor Sir Patrick Bateson, President of the Zoological Society of London, published an open letter in the Observer signed by 30 eminent scientists. The scientists urge the government to reconsider its policy because "the complexities of TB transmission mean that licensed culling risks increasing cattle TB rather than reducing it" (Bateson et al. 2012). A key function of expertise in policy making is to depoliticise policy. In bovine TB policy, Wilkinson has claimed that rather than expertise depoliticising policy, the expertise itself has become politicised (Wilkinson 2007).

Grant (2009) and Cassidy (2012) have discussed how the public's understanding of the badger has been constructed and how this influences policy. Cassidy claims there are two opposing constructions of the badger. The 'good badger' is epitomised in Kenneth Grahame's The Wind in the Willows. In contrast, the 'bad badger' is a carnivore, a disruptive digger and a disease carrier (Cassidy 2012, p. 192). Grant conducted archival research of MAFF files into policy makers' constructions of the badger. He found that MAFF and Defra use the construct of an 'old rogue badger':

The concept of the 'rogue badger' is still present in frames of reference as it was referred to in a discussion between the author and the Defra bovine TB team in May 2009. The myth of the rogue badger permitted the construction of an image of a bad, deviant or antisocial badger, a 'senile and virtually toothless' creature... whose actions could be presented as a basis for intervention against a cherished animal. (Grant 2009, p. 563)

Grant claims that such framings of the badger need to be taken into account in the policy process and argues that technocratic welfare-based models of policy making have contributed to "long term intractable policy failure" (Grant 2009, p. 563). Gibbens and Hepple appear to concede such policy failure by describing bovine TB as a "wicked problem" (Hepple and Gibbens 2013, pp. 235-237). The authors-a Defra official and the Chief Veterinary Officer-write:

Some policy issues concerning animals can also be identified as wicked problems. It is often the differing values of the animals involved that can lead to issues developing into wicked problems. It becomes an even greater mess when different species with different values to different sectors of society are intimately involved in the same wicked problem. (Hepple and Gibbens 2013, p. 236)

These multi-factorial and complex dimensions of bovine TB policy have led to Britain having three different policies on bovine TB (Spencer 2011). In England, 
badger culls were first conducted in 2013 and are on-going. In Wales, the Labour government rejected a cull and has pursued a badger vaccination trial and increased cattle controls. From 2008 to 2015, the bovine TB incidence in Wales decreased by around 50\% (APHA 2015, pp. 6, 18). More recently due to a global shortage of the BCG vaccine, badger vaccination has been halted and the Welsh government has agreed to targeted culling of badgers on some chronically-infected farms (Welsh Government 2017). Scotland, which has a far lower incidence of bovine TB, has been granted TB-free status.

\section{The Justification for Animal Welfare Impact Assessment and Ethical Analysis of Bovine TB and Badger Control Policy}

Natural England advice to Defra prior to the 2013 pilot culls estimated that if culling were successfully completed, 30-50 badgers would be killed for every bovine TB herd breakdown that is prevented. The same report states that the level of culling in the badger culls will cause a 14-27\% reduction of the badger population in England, and a $25-54 \%$ reduction in the South West and West Midlands (Natural England 2011, p. 5). Figures for the number of badgers culled and the number of cattle that avoid slaughter due to badger culling are documented in an Animal Welfare Impact Assessment presented in McCulloch and Reiss (2017d). Here, it is important simply to state that badger culling is clearly an ethical issue. A former BCVA President recognises the ethics inherent in badger culling:

Well, you know, making a decision to kill part of our indigenous wildlife, no matter how well it's controlled, and how humanely, is a massive decision. We'd live in a pretty lousy society I think if we just said, "Yeah we'll go and kill badgers", and nobody turned a hair. So I think it does have to be considered very, very carefully and I guess these individual politicians just have to weigh up the ethical and the scientific issues [Former BCVA President]

We argue that the weighing up of ethical issues needs to be conducted by independent experts using established moral frameworks. Policy on badger control should not, and indeed cannot, be based exclusively on the scientific evidence base (e.g. the RBCT), economics (e.g. a cost-benefit analysis) nor public opinion (e.g. a Defra 2006 public consultation). Furthermore, it is problematic for a number of reasons to leave politicians to 'weigh up ethical and scientific issues'. Ultimately, in the final analysis, policy on badger control is necessarily a moral issue that should be analysed in the context of the following question:

Ethically, what is the right, or most justifiable policy on badger control, considering impacts on all morally relevant affected groups?

The natural science evidence base, economic tools such as cost-benefit analysis and public opinion should all inform policy. However, given that cattle and badgers are, like humans, sentient, government policy options should be appraised in the 
context of the above question. Necessarily, an informed answer to this question entails the following:

1. An Animal Welfare Impact Assessment (AWIA) to assess the impacts of policy options on cattle and badger populations

2. Robust ethical analysis, informed by the empirical evidence base, of badger control policy options.

The exclusion of either 1 or 2 , or indeed both, leads to the exclusion of the interests of animals in policy making. The public has a legitimate moral concern about how public policy impacts sentient animals. Therefore, the exclusion of 1 and/ or 2 leads to the exclusion of legitimate values held by the democratic public about how society treats animals. The AWIA is described and applied to bovine TB and badger control policy options in McCulloch and Reiss (2017d). Ethical analysis is applied to bovine TB policy using established frameworks in McCulloch and Reiss (2017a, b, c).

\section{Conclusion}

Bovine TB is the most economically important animal health policy issue in England. The disease cost the UK government some $£ 500$ million between 2004 and 2014 and this cost is set to double over the next decade. Badgers are a wildlife source of infection but the government's badger culling policy has proven controversial. The Independent Scientific Group (ISG), after an 8 year field trial, recommended against badger culling, concluding that bovine TB can be controlled and ultimately eradiated by cattle-based measures alone. However, a review by the Chief Scientist, David King, found that badger culling could contribute to bovine TB control.

The 2005-2010 Labour government followed the ISG recommendations and resisted calls by the NFU and BVA for a badger cull. However, the 2010 Coalition government and the 2015-present Conservative government pursued a farmer-led badger culling policy. The IEP reported that the first year of the badger culls in west Somerset and west Gloucestershire failed in terms of effectiveness and humaneness. Despite this, the government has continued with a cull and rolled it out to a total of 10 areas.

The scientific evidence base, economics and ethics of badger culling is highly contested by stakeholders. Government and the pro-culling lobby claim that badger culling is necessary to control bovine TB. They argue that badger culling is justified on the basis of scientific evidence, economic benefits, veterinary advice and the experience of countries such as New Zealand. Those opposed to a badger cull argue that culling is not supported by the scientific evidence base, is not cost effective, and is inhumane. They argue that vaccination is more effective and humane than culling and point to Wales, which has substantially reduced its incidence of bovine TB without culling. 
In this paper, we argue that Animal Welfare Impact Assessment (AWIA) and independently conducted ethical analysis should be necessary components to inform animal health and welfare policy such as bovine TB and badger control. AWIA provides objective information about the welfare impacts of policy options, for both cattle and badgers. Objective data relating to welfare impacts are a necessary component of policy making that considers the interests of affected sentient animals. Furthermore, no matter what the impacts on affected parties, bovine TB and badger control is necessarily a moral issue. There are clear winners and losers in the various policy options. Hence, independent ethical analysis, conducted using established moral frameworks, is a necessary element of just policy making.

Acknowledgements The first author would like to thank the Royal Veterinary College, University of London, which funded work for a Ph.D. that this paper is based on. He would also like to thank the animal health and welfare policy actors interviewed during the course of the research. Finally, we would like to thank the late Christopher Wathes, who was one of the first author's Ph.D. supervisors.

Open Access This article is distributed under the terms of the Creative Commons Attribution 4.0 International License (http://creativecommons.org/licenses/by/4.0/), which permits unrestricted use, distribution, and reproduction in any medium, provided you give appropriate credit to the original author(s) and the source, provide a link to the Creative Commons license, and indicate if changes were made.

\section{References}

APHA. (2015). Epidemiology of bovine tuberculosis in Wales: Annual surveillance report. London: Animal and Plant Health Agency.

Barkham, P. (2015). Experts call for immediate halt to $£ 7,000$-per-badger cull. The Guardian. Retrieved from https:/www.theguardian.com/environment/2015/sep/02/badger-cull-experts-call-forimmediate-halt-programme.

Bateson, P., Begon, M., Blackburn, T., Bourne, J., Sutherland, W., Burke, T., et al. (2012). Culling badgers could increase the problem of TB in cattle: Badger culling risks becoming a costly distraction from nationwide TB control. The Observer. Retrieved from http://www.theguardian.com/ theobserver/2012/oct/14/letters-observer?guni=Article:in\%20body\%20link.

Bateson, P., Krebs, J., Bourne, J., Munro, R., Sillero, C., Crispin, S., et al. (2015). Badger cull is flawed and must now stop. The Guardian. Retrieved from https://www.theguardian.com/uk-news/2015/sep/ 02/badger-cull-is-flawed-and-must-now-stop.

BBC. (2013). Badgers 'moved goalposts' says minister Owen Paterson. BBC. Retrieved from http://www. bbc.co.uk/news/uk-england-24459424.

BBC News. (2015). Badger culls costs taxpayer more than $£ 16 \mathrm{~m}$. Retrieved 29 June 2017, from BBC http://www.bbc.co.uk/news/uk-england-34128594.

Bourne, F. J., Donnelly, C. A., Cox, D. R., Gettinby, G., McInerney, J. P., Morrison, W. I., et al. (2007). Bovine TB: The scientific evidence-final report of the independent scientific group on cattle TB. London: Independent Scientific Group on Cattle TB.

Boyd, I., \& Gibbens, N. (2012). Badger cull furore is distracting attention from the real problem. The Guardian. Retrieved from http://www.theguardian.com/environment/2012/oct/11/badger-cullfurore.

BVA. (2015). BVA council position on the pilot badger culls and badger culling policy in England. London: British Veterinary Association.

Cassidy, A. (2012). Vermin, victims and disease: UK framings of badgers in and beyond the bovine TB controversy. Sociologia Ruralis, 52(2), 192-214. 
Conservative Party. (2015). The conservative party manifesto 2015: Strong leadership, a clear economic plan, a brighter, more secure future. London: Conservative Party.

Conservative Party. (2017). Forward together: Our plan for a stronger Britain and a prosperous future. London: The Conservative and Unionist Party.

Defra. (2006). Public consultation on controlling the spread of bovine tuberculosis in cattle in high incidence areas in England: Badger culling-summary of responses. London: Defra.

Defra. (2010a). Bovine tuberculosis: The government's approach to tackling the disease and consultation on a badger control policy. London: Defra.

Defra. (2010b). Bovine tuberculosis: The government's approach to tackling the disease and consultation on a badger control policy-Annex E, veterinary assessment on culling. London: Defra.

Defra. (2011). The government's policy on bovine TB and badger control in England. London: Defra.

Defra. (2013). Strategy for achieving “officially bovine tuberculosis free” status for England: An 'edge area' strategy. London: Defra.

Defra. (2014a). Press release: Plans to eradicate bovine TB in England unveiled [Press release]. Retrieved from https://www.gov.uk/government/news/plans-to-eradicate-bovine-tb-in-england-unveiled.

Defra. (2014b). The strategy for achieving officially bovine tuberculosis free status for England. London: Defra.

Defra. (2016a). Badger control policy: Value for money analysis 2016. London: Defra.

Defra. (2016b). Further measures to eradicate bovine TB [Press release]. Retrieved from https://www. gov.uk/government/news/further-measures-to-eradicate-bovine-tb.

Donnelly, C. A., Woodroffe, R., Cox, D. R., Bourne, F. J., Cheeseman, C. L., Clifton-Hadley, R. S., et al. (2006). Positive and negative effects of widespread badger culling on tuberculosis in cattle. Nature, 439(7078), 843-846. doi:10.1038/nature04454.

Dunnet, G. M., Jones, D. M., \& McInerney, J. P. (1986). Badgers and bovine tuberculosis: Review of policy. London: HM Stationery Office.

Dyer, D. (2016). Badgered to death: The people and politics of the badger cull. London: Canbury Press.

Godfray, H. C. J., Donnelly, C. A., Kao, R. R., Macdonald, D. W., McDonald, R. A., Petrokofsky, G., et al. (2013). A restatement of the natural science evidence base relevant to the control of bovine tuberculosis in Great Britain. In Proceedings of the Royal Society B: Biological Sciences, vol. 280, no. 1768 .

Grant, W. (2009). Intractable policy failure: The case of bovine TB and badgers. The British Journal of Politics \& International Relations, 11(4), 557-573.

HC. (2013). Badger culling (SNSC-5873). London: House of Commons Library.

HC Deb. (2008). Bovine TB. Hansard, 478 (col. 1153).

HC Deb. (2014). Badger Cull. Hansard, 577 (col. 456).

HC Deb. (2016). Badger Culling/Bovine TB. Hansard, 614 (col. 141WH).

HC Deb. (2017). Badger Culling. Hansard, 624 (col. 1WH).

Hepple, S., \& Gibbens, N. (2013). Animal ethics and the government's policy: 'To guard and protect'. In C. M. Wathes, S. A. Corr, S. A. May, S. P. McCulloch, \& M. C. Whiting (Eds.), Veterinary and animal ethics: Proceedings of the first international conference on veterinary and animal ethics, September, 2011 (pp. 229-244). Oxford: Wiley-Blackwell.

HM Gov. (2010). The coalition: Our programme for government. London: The Cabinet Office.

IEP. (2014). Pilot Badger culls in Somerset and Gloucestershire: Report by the independent expert panel. London: Independent Expert Panel.

Kay, A. (2017). Defra secretary michael gove on the customs union, badger cull, support payments and more. FG Insight. Retrieved from https://www.fginsight.com/news/exclusive-interview-defrasecretary-michael-gove-on-the-customs-union-badger-cull-support-payments-and-more-22102.

King, D. (2007). Bovine tuberculosis in cattle and badgers. London: Defra.

Krebs, J. R., Anderson, R., Clutton-Brock, T., Morrison, I., Young, D., \& Donnelly, C. (1997). Bovine tuberculosis in cattle and badgers. London: Independent Scientific Review Group.

Labour Party. (2017). For the many not the few. London: Labour Party.

McCulloch, S. P., \& Reiss, M. J. (2017a). Bovine tuberculosis and badger culling in England: A utilitarian analysis of policy options. Journal of Agricultural \& Environmental Ethics. doi:10.1007/s10806017-9680-9.

McCulloch, S. P., \& Reiss, M. J. (2017b). Bovine tuberculosis and badger culling in England: An animal rights-based analysis of policy options. Journal of Agricultural \& Environmental Ethics. doi:10. 1007/s10806-017-9683-6. 
McCulloch, S. P., \& Reiss, M. J. (2017c). Bovine tuberculosis policy in England: Would a virtuous government cull Mr Badger? Journal of Agricultural \& Environmental Ethics. doi:10.1007/s10806017-9682-7.

McCulloch, S. P., \& Reiss, M. J. (2017d). The development of an Animal Welfare Impact Assessment (AWIA) tool and its application to bovine tuberculosis and badger control in England. Journal of Agricultural \& Environmental Ethics. doi:10.1007/s10806-017-9684-5.

McEldowney, J., Grant, W., \& Medley, G. (2013). The regulation of animal health and welfare: Science, law and policy. Abingdon: Routledge.

Natural England. (2011). The impact of culling on badger (Meles meles) populations in England and measures to prevent their 'local disappearance' from culled areas: Supplementary advice provided under the Protection of Badgers Act 1992 and Wildlife \& Countryside Act 1981 (as amended): Natural England.

Reynolds, D. (2006). A review of tuberculosis science and policy in Great Britain. Veterinary Microbiology, 112(2), 119-126.

Spencer, A. (2011). One body of evidence, three different policies: Bovine tuberculosis policy in Britain. Politics, 31(2), 91-99.

Welsh Government. (2017). Strengthened approach to tackling bovine TB in Wales announced. Retrieved 30 June, 2017, from http://gov.wales/newsroom/environmentandcountryside/2017/170620strengthened-approach-to-tackling-bovine-tb-in-wales-announced/?lang=en.

Wilkinson, K. (2007). Evidence based policy and the politics of expertise: A case study of bovine tuberculosis Centre for Rural Economy Discussion Paper Series (Vol. 12). Newcastle: Centre for Rural Economy.

Woodroffe, R., Donnelly, C. A., Cox, D. R., Bourne, F. J., Cheeseman, C. L., Delahay, R. J., et al. (2006). Effects of culling on badger Meles meles spatial organization: Implications for the control of bovine tuberculosis. Journal of Applied Ecology, 43(1), 1-10. doi:10.1111/j.1365-2664.2005.01144.x.

Zuckerman, O. M. (1980). Badgers, cattle and tuberculosis. London: HM Stationary Office. 